\title{
Spatial modeling of extinct Southeast Asian Hobbit Homo floresiensis habitat suitability based on its diet availability and climatic parameters as a proxy
}

Andri Wibowo

Ecology Laboratory, Faculty of Mathematics and Natural Sciences, Universitas Indonesia, 16424, Depok, West

Java, Indonesia.

Email: andriwibowocbc@gmail.com

\begin{abstract}
The discovery of a new prehistoric species of the genus Homo remains a significant matter of intense interest. One of significant discovery recently is the Homo floresiensis, representing a small-bodied and small-brained hominin, excavated, and found in Liang Bua Cave in Flores Island, East Nusa Tenggara, Indonesia. This species height was only about $106 \mathrm{~cm}$ (3'6") and the weight was 30-40 kg (66-86 lbs). $H$. floresiensis was known consumed extant murine rodents as its diets as this was evidence found in Liang Bua Cave. Then this study aims to model the H. floresiensis suitable habitat using maximum entropy method and 2 extant murine rodents, Rattus exulans and $R$. rattus as a proxy. The results show that the most suitable habitats for $H$. floresiensis indicated by suitable habitat values close to 1 were concentrated in the central of Flores Island that was overlapped with mountainous areas with elevation ranging from 1500 to $2000 \mathrm{~m}$. These suitable habitats were also overlapped with dense vegetation covers, volcanic rock, and Kiro rock formation. Climatic parameters that limit the distributions of $H$. floresiensis were annual mean temperature, isothermality, minimum temperature of coldest period, and precipitation seasonality. Parts of Flores Island with the low temperature below $20{ }^{0} \mathrm{C}$ were favorable for $H$. floresiensis while an increase in isothermality limits the $H$. floresiensis distributions.
\end{abstract}

Keywords: habitat, H. floresiensis, Liang Bua Cave, maximum entropy, murine

\section{Introduction}

Hobbit is a nickname of hominin species, identified as Homo floresiensis excavated and found from Flores Island or administratively was under East Nusa Tenggara Province, Indonesia. This species was formerly known as a microcephalic dwarf modern human being (Colin 2007, Baab 2012) and assumed as an ancestor of Rampasa tribe that still living today in Flores Island. Whereas recent studies confirmed that $H$. floresiensis most closely resembles hominin species from the Late Pliocene and Early Pleistocene including species of H. habilis, H.ergaster, and H. georgicus (Argue et al. 2006).

In Indonesia, Flores is one of many Wallacean islands located on east of Wallace's Line and west of Lydekker's Line. Wallacean islands are important for biogeography sciences since it has been connected via land bridges to either the Asian continent to the west or the Greater Australian continent to the east. This longstanding separation from the surrounding continents either with Australia or Asia has severely limited the ability of species mainly animals to disperse either into or away from the Wallacean islands. As a result, Flores Island was isolated and in Flores there were only a small number of mammal and reptile species during the entire Pleistocene. Those species included komodo dragons and other smaller monitor lizards, crocodiles, several species of Stegodon, (an extinct close relative of modern elephants), giant tortoise, and several kinds of small, medium, large-bodied rats, and $\mathrm{H}$. floresiensis (Bergh et al. 2001).

Recently, the diets of $H$. floresiensis have been identified. Fossils of animals were excavated and found nearby $H$. floresiensis fossils were found. Excavation in Liang Bua resulted in 230,000 bone fragments (Hafsari 2017) that were identified belongs to murine rodents under Rodentia Order, Muridae Family, and Murinae Subfamily or known as rats (Veatch 2014). At least there were 6 rat Generas including Papagomys with species of $P$. armandvilley and $P$. theodorverhoeveni, Spelaeomys florensis, Hooijeromys nusatenggara, Komodomys rintjanus, Paulamys naso, and Rattus including Rattus hainaldi and Rattus exulans. Humerus and femur of medium (100-300 g) followed by small (<100 g) murine rodents (Veatch et al. 2019) were accounted for almost half of the fossils found in Liang Bua. Small murine was identified as Rattus hainaldi and Rattus exulans and medium sized was Rattus rattus. 
Hafsari (2017) argued that the presence of murine rodents in Liang Bua due to consumption of murines by cave occupants in this case was presumably $H$. floresiensis. Even at the current time, native people nearby Liang Bua still consume rats. Despite H. floresiensis has been extensively studied, information on where did these hominin species was previously distributed was still limited. Here this study aims to estimate the suitable habitat of extant $H$. floresiensis using its diet, a murine rodent species, distribution, as a proxy using predator prey interaction distribution model (Trainor et al 2014).

\section{Methodology \\ Study area}

The location was a Flores Island (Figure 1) located in the eastern part of Indonesia. This island has a size of $13,540 \mathrm{~km}^{2}$ and has geographical coordinate of $120^{\circ}$ and $122^{\circ}$ longitude and $8.3^{\circ}$ and $8.7^{\circ}$ latitude. The highest point was $2,370 \mathrm{~m}$ located in the west part of the island and observed in mount Poco mandasawu. The landscape of Flores Island was a combination of low land and mountainous region with hilly landscape. The climate of Flores Island is tropical dry with a fairly long dry season, which is about 8 months per year with uneven distribution of rainfall. The air temperature varies between $21.2{ }^{\circ}$ Celsius $33.4^{\circ}$ Celsius.

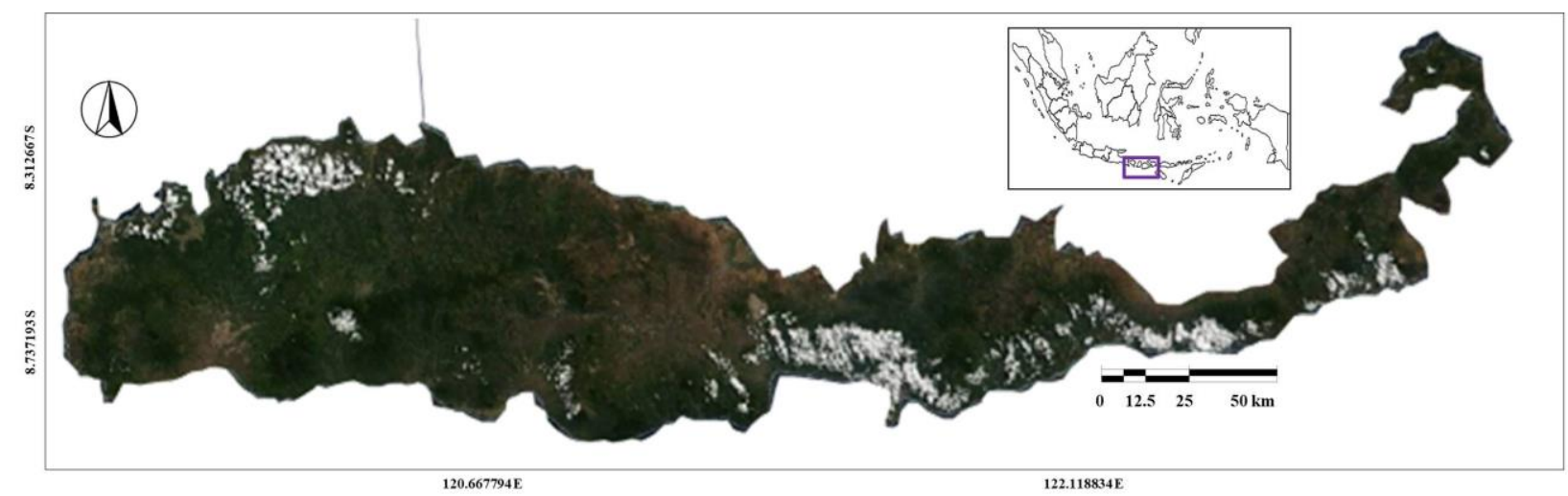

Figure 1. Study area in Flores Island, East Nusa Tenggara, Indonesia

\section{Murine data retrieval}

This study used the presence data of 2 murine rodent species identified as the potential $\mathrm{H}$. floresiensis diet. Those murine species included extant Rattus exulans and Rattus rattus. The presence and locality data of those species were retrieved from Global Biodiversity Information Facility (Boitani et al. 2011, Prieto-Torres \& Pinilla-Buitrago 2017, Truong et al. 2017). The retrieved data included the geographical coordinate of those murines recorded in Flores island. The coordinates including longitude and latitude then mapped using GIS to be used for further distribution modeling analysis.

\section{Elevation, geology, and tree cover data retrieval}

This study uses several environmental data including elevation, geology, and tree cover thematic data. The elevation data of Flores Island denoted in m was retrieved from Shuttle Radar Topography Mission (Patel \& Sarkar 2010). The geological data including rock formation and aquifer lithology were obtained from the Geological Agency of Indonesia. The tree covers data indicating the presence of forest in Flores Island were retrieved using multispectral satellite imagery from the Landsat 7 thematic mapper plus (ETM+) sensor (Hansen et al. 2013).

\section{Murine distribution modeling}

The murine distribution was estimated using murine presence data retrieved from GBIF and mapped using GIS as described in previous steps. Distribution estimation of species was developed followed methods by Zhang et al. (2019). The potential murine distribution was modeled using the principle of 
maximum entropy to calculate the most likely distribution of the murine species in the function of occurrence localities and environmental variables. Suitability habitat was classified and ranked from 0 as the least suitable to the 1 for the most suitable habitat. The model used 15 climatic variables (Beaumont et al. 2005) retrieved from WorldClim database. The complexity of the model was tested using the Akaike information criterion values (AICc) corrected under different parameter conditions. AIC is a standard to measure the goodness of statistical model fitting and it generally gives priority to the parameters with small AIC values for simulation

\section{Results and Discussions}

Rattus exulans and Rattus rattus were 2 murine species that were still living across Flores Island landscape. Based on the GBIF records, there were 5 locations where both murine species occurrences were overlapped. While $R$. rattus presence distribution was wider since this species was also found in the most western parts of the island (Figure 2.a.). Both species have a wide distribution from east to central and west of Flores Island.

The landscape of Flores Island was mostly dominated by a hilly landscape that was very common in west and central parts, and some patchy hilly landscapes in the east part. $R$. exulans and $R$. rattus occurrences and Liang Bua Cave location at present time were overlapped with the hilly landscape. Both murines were occupying hilly landscapes in the west and east parts of the island (Figure 2.b.). Flores Island was comprised of several rock formations. In this island, Liang Bua was located within Kiro formation and surrounded by Lekopiko, Bari, and younger volcanic formations. Correspondingly, both murines were also presented within Kiro formation (Figure 2.c). Kiro formation on Flores Island was characterized by deposits of volcanic materials (Figure 2.d) and breccia rocks (Suharji et al. 2013) and this indicates that this rock formation was shaped and formed through a volcanic process rather than tectonic process (Hartono 2011). Volcanic land was suitable for species since volcanic materials contain substances that can increase land fertility and support vegetation that can be consumed by murines. Rats are among species that first colonize and more adapt to the volcanic land ecosystems (Thornton et al. 2001).

Most Flores Island still has dense vegetation covers (Figure 2.e). Whereas central parts of the island were the only parts that have less covers. Murine species consumed by $H$. floresiensis were preferring mostly habitats with tree covers. While $R$. rattus has wider tolerance since this species was also found in open areas with less tree covers in the most western parts of the island where $R$. exulans was not present in here.

Figure 2.f presents the suitable habitats for murine rodents that may represent the suitable habitats for $H$. floresiensis in Flores Island. The suitable habitats were estimated based on maximum entropy analysis. It was estimated that most west, central, and east parts of Flores Island mainly in central parts were estimated suitable for murines and presumably its pedators, the $H$. floresiensis. Coastal parts were the only areas that were not suitable. The highest parts and the most suitable habitats indicated by suitable habitat values close to 1 were concentrated in the central of Flores Island that was overlapped with mountainous areas with elevation ranging from 1500 to $2000 \mathrm{~m}$.

The results of the maximum entropy indicated the climatic parameters (Figure 3) that contributed more to the distribution and habitat suitability of murines were annual mean temperature, isothermality, minimum temperature of coldest period, and precipitation seasonality. Murine habitat suitability was having linear correlation with those parameters. Parts of Flores Island with the low temperature below 20 ${ }^{0} \mathrm{C}$ were favorable for murines while an increase in isothermality parameter limits the murine distributions. 


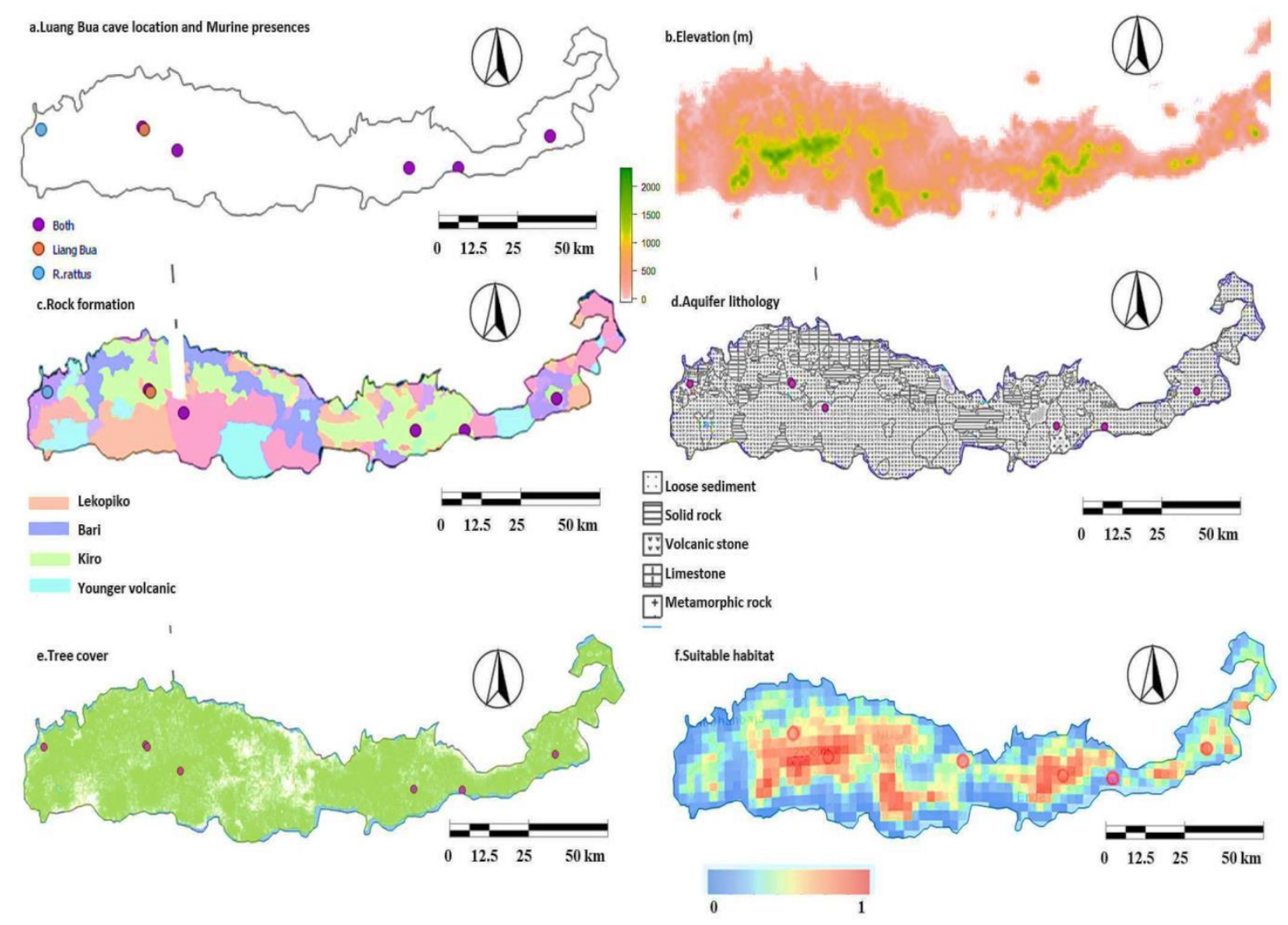

Figure 2. Rotate clock wise: (a) Liang Bua cave location (orange dot) and Murine presences in Flores Island; (b) Elevation (m) of Flores Island; (c) Rock formation of Flores Island; (d) Aquifer lithology of Flores Island; (e) Tree covers of Flores Island; (f) Estimated habitat suitability of Southeast Asian Hobbit based on Murine species ( $R$. rattus and $R$. exulans) estimated species distribution modeling.
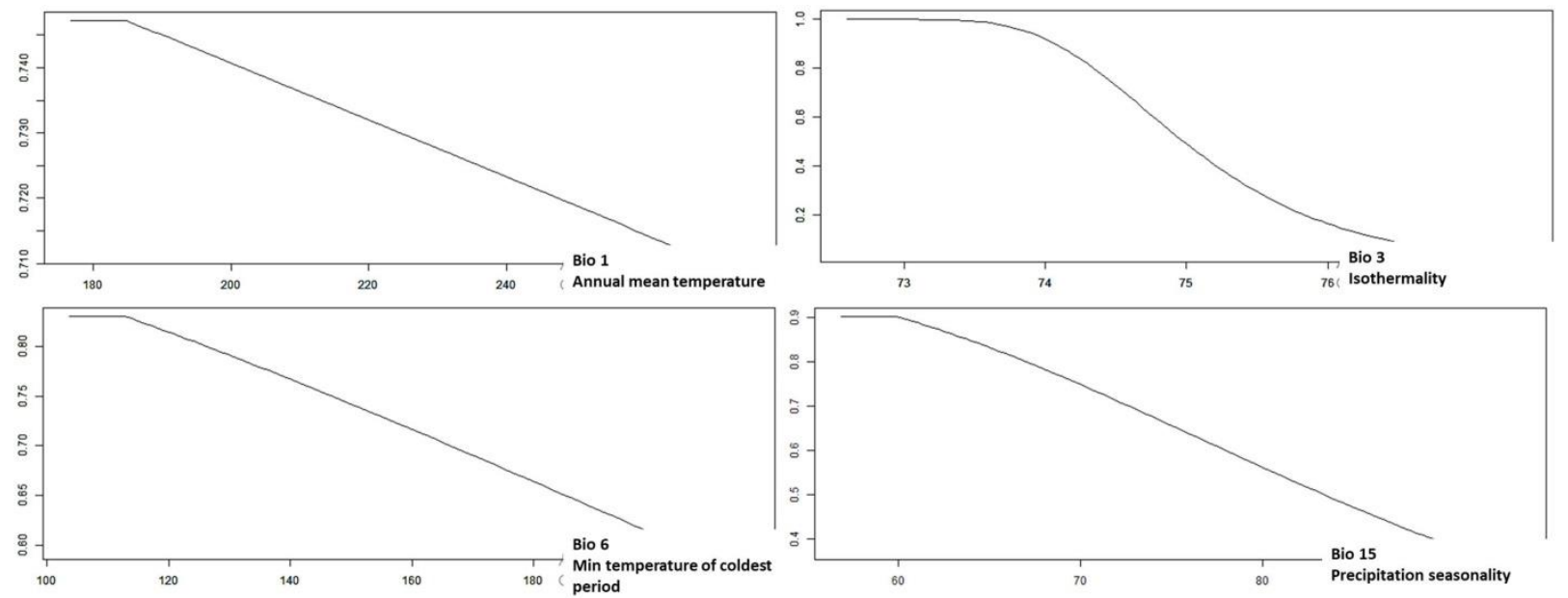

Figure 3. Climatic parameters affecting the habitat suitability and distributions of $R$. rattus and $R$. exulans in Flores Island 


\section{Conclusion}

Two extant murine rodents, $R$. rattus and $R$. exulans that formerly were consumed by extinct $H$. floresiensis can be used as a proxy to estimate the suitable habitats for $H$. floresiensis in Flores Island. The modeled suitable habitats were overlapped with high elevation, vegetation covers, and Kiro rock formations. High annual mean temperature, high isothermality, and high precipitation seasonality were climatic parameters that limit the distribution and suitable habitats of $R$. rattus and $R$. exulans and presumably their predators, the $H$. floresiensis.

\section{References:}

Argue D, Donlon D, Groves C, Wright R. 2006. Homo floresiensis:Microcephalic, pygmoid, Australopithecus, or Homo? J Human Evol 51:360-374.

Baab KL. 2012. Homo floresiensis: Making Sense of the Small-Bodied Hominin Fossils from Flores. Nature Education Knowledge 3(9):4

Beaumont L, Hughes L, Poulsen M. 2005. Predicting species distributions: Use of climatic parameters in BIOCLIM and its impact on predictions of species' current and future distributions. Ecological Modelling. 186: 251-270.

Boitani L, Maiorano L, Baisero D, Falcucci A,Visconti P, Rondinini C. 2011. What spatial data do we need to develop global mammal conservation strategies?. Philosophical Transactions of The Royal Society B Biological Sciences. 266. 2623-2632.

Colin G. 2007. The Homo floresiensis Controversy. HAYATI Journal of Biosciences. 14. 10.4308/hjb.14.4.123.

Hafsari M. 2017. Rats as Source of Calory of Hominins in Liang Bua, West Flores, Nusa Tenggara TimurNi. Forum Arkeologi. 30. 113. 10.24832/fa.v30i2.199.

Hansen MC, Potapov PV, Moore R, Hancher M, Turubanova SA, Tyukavina A, Thau D, Stehman SV, Goetz SJ, Loveland TR, Kommareddy A, Egorov A, Chini L, Justice CO, Townshend JRG. 2013. High-Resolution Global Maps of 21st-Century Forest Cover Change. Science 342: 850-53.

Hartono HG.2010. Penelitian Awal Gunung Api Purba Di Daerah Manggarai Barat, Flores, Nusa Tenggara Timur, Indonesia. MTG 3(1).

Patel P \& Sarkar A. 2010. Terrain characterization using SRTM data. Journal of the Indian Society of Remote Sensing. 38. 11-24.

Prieto-Torres DA, Pinilla-Buitrago G. 2017. Estimating the potential distribution and conservation priorities of Chironectes minimus (Zimmermann, 1780) (Didelphimorphia: Didelphidae). Therya 8(2): 131-144.

Suharji, Nurdin M, Karunianto AJ, Sartapa, Sudarto S. 2013. Pelacakan Air Tanah Di Desa Mbuit, Kabupaten Manggarai Barat, Provinsi Nusa Tenggara Timur. Eksplorium 34(2): 121-136

Thornton IWB, Cook S, Edwards JS, Harrison RD, Schipper C, Shanahan M, Singadan R, Yamuna R. 2001. Colonization of an island volcano, Long Island,Papua New Guinea, and an emergent island, Motmot, in its caldera lake. VII. Overview and discussion. Journal of Biogeography 28:1389-1408.

Trainor A, Schmitz O, Ivan J, Shenk T. 2014. Enhancing species distribution modeling by characterizing predatorprey interactions. Ecol Appl. 24. 204-16. 10.1890/13-0336.1.

Truong TTA, Giles H. St, Margaret A. 2017. Contemporary Remotely Sensed Data Products Refine Invasive Plants Risk Mapping in Data Poor Regions Frontiers in Plant Science. Frontiers in Plant Science 8.

Van den Bergh G, Vos J, Aziz F, Morwood M. 2001. Elephantoidea in the Indonesian region: new Stegodon findings from Flores. The World of Elephants, International Congress, Rome 2001Volume: The world of elephants. Proceedings of the 1st International Congress, Rome.

Veatch EG. 2014. A Morphological Analysis of the Humerus and Calcaneus of Endemic Rats from Liang Bua, Flores, Indonesia. Tesis, The George Washington University.

Veatch EG, Tocheri MW, Sutikna T, McGrath K, Saptomo EW, Jatmiko, Helgen KM. 2019. Temporal shifts in the distribution of murine rodent body size classes at Liang Bua (Flores, Indonesia) reveal new insights into the paleoecology of Homo floresiensis and associated fauna. Journal of Human Evolution 130: 45-60.

Zhang J, Jiang F, Li, G. 2019. Maxent modeling for predicting the spatial distribution of three raptors in the Sanjiangyuan National Park, China. Ecol Evol. 9: 6643- 6654. 